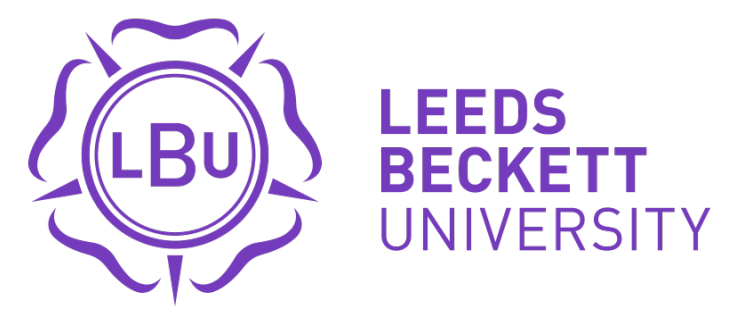

Citation:

Alsufyani, R and Safdari, F and Chang, V (2015) Migration of cloud services and deliveries to higher education. In: Proceedings of ESaaSA 2015 - 2nd International Workshop on Emerging Software as a Service and Analytics, In conjuction with the 5th International Conference on Cloud Computing and Services Science - CLOSER 2015. UNSPECIFIED, 86 - 94. ISBN 9789897581106

Link to Leeds Beckett Repository record:

https://eprints.leedsbeckett.ac.uk/id/eprint/2201/

Document Version:

Book Section (Published Version)

The aim of the Leeds Beckett Repository is to provide open access to our research, as required by funder policies and permitted by publishers and copyright law.

The Leeds Beckett repository holds a wide range of publications, each of which has been checked for copyright and the relevant embargo period has been applied by the Research Services team.

We operate on a standard take-down policy. If you are the author or publisher of an output and you would like it removed from the repository, please contact us and we will investigate on a case-by-case basis.

Each thesis in the repository has been cleared where necessary by the author for third party copyright. If you would like a thesis to be removed from the repository or believe there is an issue with copyright, please contact us on openaccess@leedsbeckett.ac.uk and we will investigate on a case-by-case basis. 


\title{
MIGRATION OF CLOUD SERVICES AND DELIVERIES TO HIGHER EDUCATION
}

\author{
Raed Alsufyani ${ }^{1}$, Fash Safdari ${ }^{1}$ and Victor Chang ${ }^{1}$ \\ ${ }^{1}$ School of Computing, Creative Technologies and Engineering, Leeds Beckett University, Headingley, Leeds LS6 3QR, UK \\ r.alsufyani5478@students.leedsbeckett.ac.uk; \{ F.Safdari,V.I.Chang\}@leedsbeckett.ac.uk
}

\begin{abstract}
Keywords: Cloud computing, Cloud computing business framework, quality of service, quality of experience.
Abstract: This paper discusses the adoption of cloud computing in education. It emphasizes the view that cloud computing is vital in the education sector because of its ability to reduce the overall costs of IT infrastructure installation and maintenance, improvement of efficiency, and the sharing of IT resources among students. The flexibility of cloud computing and its reliability makes it more appropriate for use in the educational environment. The Leeds Beckett University cloud project utilizes the SAS Educational Value-Added Assessment System, which gives lecturers the opportunity to deliver accurate content to students while monitoring their progress. Contemporary educational institutions should look forward to improve their research and education through cloud computing.
\end{abstract}

\section{INTRODUCTION}

The emergence of cloud computing and its application to diverse fields such as education has brought about a lot of opportunities for improving efficiency of service provision (Sultan, 2010). The key categories of cloud computing that institutions could adopt include the public cloud, the private cloud, the hybrid cloud, and the community cloud. Educational institutions, including colleges and universities have been quick to adopt cloud computing to boost efficiency, minimize IT costs, and improve their research and academic processes. For instance, Kurelović et al. (2013) estimates that cloud computing in K-12 students could consume up to $35 \%$ of the IT budget in the coming few years. This is an indication of the expanding cloud computing services in education. Ercan (2010) agrees that the security, reliability, and economic nature of cloud computing play a vital role in the challenging environment of education where large volumes of data are stored. There are a few frameworks and amongst them, the Cloud Computing Business Framework (CCBF) (Chang et al., 2013 a) has been regarded as a recommended cloud adoption framework because of its ability to classify business models, portability, organizational sustainability, and the linkage of service models. The SAS Educational Value-Added Assessment System stands out as one of the best for the educational sector, as evidenced from its use at Leeds Beckett University.

This paper explicates cloud computing to highlight its meaning, classifications, reasons for university adoption, frameworks for cloud computing, and the factors for deploying cloud computing in education.

\subsection{Defining Cloud Computing}

There is no standard definition of cloud computing as many IT professionals have come up with their own definitions. However, the commonly used definition indicates that cloud computing is a cluster of distributed computers that offer ondemand resources and services over a networked medium commonly the internet (Sultan, 2010). It is worth understanding that it entails the deployment of groups of remote servers and software networks, which allow the centralized storage of data and access to computer services through the internet (Mokhtar et al. 2013).

\subsection{Classification of Cloud Computing}

Cloud computing is clearly classified into four significant categories. The first category is the public cloud. According to Chang et al. (2013), this is where the entire computing infrastructure is 
located in the cloud provider's premises and the user has no physical control over it. A public cloud tends to use shared resources and might be vulnerable to attacks.

The private cloud comes in as the second category. This entails one particular organization using the cloud infrastructure for its different operations. It is remotely located and is not shared with other organizations. The advantage of the private cloud is that the customer has control over the infrastructure, as it could be hosted internally or externally (Chen et al. 2014).

The third category is the hybrid cloud, which implies utilizing both the private and the public cloud depending on the purposes they serve. For instance, an organization could use the public cloud in activities such as customer interaction while securing its network using the private cloud.

The last significant category is the community cloud that entails the sharing of infrastructure between organizations with shared data, and other data management concerns. The advantage is that it could be hosted internally or externally depending on the institution's choice (Singhal et al. 2013). This would be the most relevant cloud for the academic community because it significantly minimizes costs through a cost-sharing approach. The operational costs are significantly reduced because the cloud is shared across community members. The aspect of cost minimization is also seen in terms of augmenting existing data resources rather than building new internal environments (Youssef 2012). Moreover, it makes it easier for educational institutions to administer cloud and the traditional data centre environments remotely hence cutting down overall costs of operation. Again, it allows for control of the infrastructure by the institutions utilizing it (Chang et al., 2013 a). Internal control of the cloud facilitates real-time reporting and ordering through customizable management portal. Thirdly, the community cloud is relevant to educational institutions because of their effective security, privacy, and compliance. It is usually tailored in such a way that it can address unique security problems and regulatory needs relating to the institution (Singhal et al. 2013).

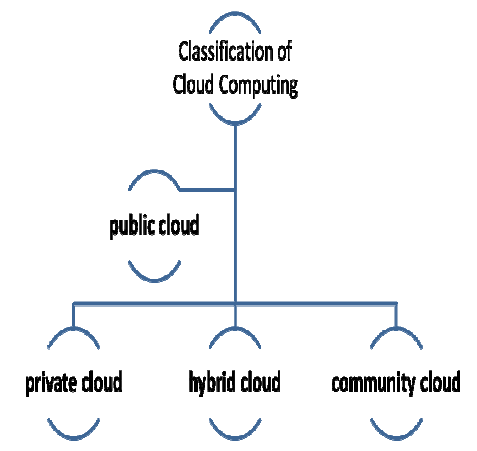

Fig1: Classification of Cloud Computing

In line with these categories of clouds, institutions could enjoy various service models. The first is the Infrastructure as a Service (IaaS). Almorsy et al. (2011) affirm that this category offers relevant products such as remote delivery through the internet of the entire computer infrastructure. For instance, it offers storage, virtual computers, and servers.

The second category is the Platform as a Service (PaaS). Jula et al. (2014) indicates that this service model has transformed the traditional delivery of computing services. For instance, the presence of this category has enabled cloud providers to remotely offer diverse products including the hardware, middleware, a database and the operating system (Singhal et al. 2013).

The third model is Software as a Service (SaaS). This category delivers applications through the medium of the internet as a service. Users do not need to install and maintain software, as they have the pleasure of accessing it through the internet (Youssef 2012). Overall, SaaS offers a complete application functionality stretching from productivity applications to other programs such as the Customer Relationship Management.

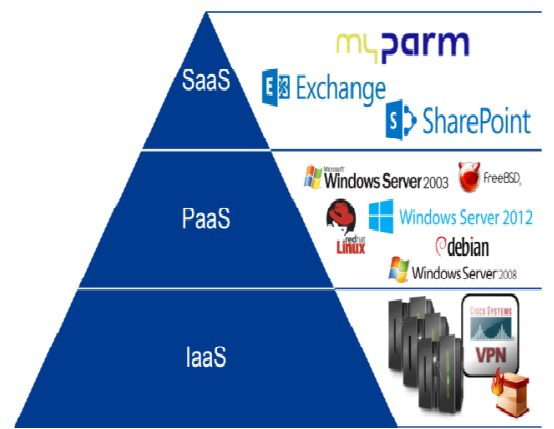

Fig.2: The Cloud-Computing-Architecture specified by the National Institute of Standards and Technology (NIST) knows three models, namely Infrastructure (IaaS), Platform- (PaaS) and Application models (SaaS). 


\subsection{Challenges of Cloud Computing}

Whilst there are potential benefits associated with public cloud computing implementation, there are also risks and uncertainties that come with public cloud computing. Moving computing resources to the cloud is not without difficulties and issues. For example, Amazon cloud services outages caused many organizations the loss of their computing resources, services and incurred economical losses (Bright 2011). The potential benefits of cloud computing need to be assessed against possible associated risks.

Geczy et al. (2013) stated performance as one of concerns associated with cloud computing. In cloud computing, computing services and resources which were typically installed, managed, and accessed within organizations premises are hosted in data centres and in the majority of cases are accessed over the Internet. Internet is a best-effort and shared communication infrastructure. The organization data traffic has to travel through many different routes and hops shared by other organizations and user traffic, packets could travel over different routes which could be saturated and arrived out of sequence, packets could be lost (Ukil et al. 2013).

These could lead to delay and jitter resulting in poor performance. Reliability of Internet also plays a major role in the reliability and availability of the public cloud services. The internet is an unpredictable network environment (Ivanus \& Iovan 2014). These inherent characteristics of internet could have a major impact on the performance of public cloud. This paper aims at surveying the applicability of cloud technology in education. It is focused on encouraging all educational institutions to embrace cloud technology because of its advantages.

\section{REASONS FOR UNIVERSITY CLOUD ADOPTION}

Many universities around the globe have moved swiftly to incorporate cloud computing into their learning and research processes. Specifically, Chang and Wills (2013) inform that cloud computing is viewed as an attractive part of research and education within universities because of its ability to allow searches and collaborative working among students. As previously discussed in section 1.2, the community cloud is the most relevant for universities because of its efficiency and cost reduction, security and privacy, and the agility in terms of service delivery (Chang et al. 2013 a;
Chang and Wills, 2013). The University of Greenwich is one of the key institutions that have adopted cloud computing into their research and learning processes. In tandem with the University of Greenwich case study, five significant reasons have motivated universities to adopt cloud computing.

The first key reason for university cloud adoption is the fact that it plays an instrumental role in the reduction of environmental and financial costs in areas where services are needed for shorter periods (Chang et al. 2013 a). This is bound to save many universities money, hence avoiding unnecessary wastage. Every university looks forward to cut down its operating costs in respect to IT and energy usage at the institution.

Secondly, many universities are adopting cloud computing because it has the capacity to make experiments more repeatable. Ercan (2010) points out with cloud computing in place, write-ups of science experiments conducted in the cloud could contain relevant applications such as the virtual machine that make them easy to replicate (Ukil et al. 2013).

Thirdly, Cloud adoption in universities is motivated by the understanding that it facilitates the sharing of the workload in cases where the university is working with another organization (Avram 2014).

Another reason for cloud adoption in universities is that it allows and simplifies the access to web applications, data centres, and service from any given location within the university. Chen et al. (2014) agrees that this makes it easier for students to engage in research without having to concentrate in a particular area.

Lastly, universities are swiftly adopting cloud computing because of its flexibility and the aspect of pay as you go. There is always room to use specialized web-based software that otherwise could not be supported by in-house policies. This enhances the level of flexibility because of reduced bureaucracies among researchers (Ivanus \& Iovan 2014).

Apart from these motivations, the most significant challenge affecting cloud computing adoption and implementation is the lack of standards. Many institutions have found it difficult to define the desired standards. There have been no concerted efforts toward the definition of desirable standards relating to technological, management, and regulatory standards related to cloud computing (Avram, 2014). This poses the risk of failure in terms of 
take off and subsequent utilization of cloud computing in school settings.

\section{FRAMEWORKS OF CLOUD COMPUTING}

One of the most effective and efficient framework that different academic institutions could adopt is the Cloud Computing Business Framework (CCBF). The Cloud Computing Business Framework would be appropriate for the academic community because it plays an instrumental role in promoting a good cloud design hence ensuring it works efficiently within the institution through the choice of a better pattern (Chang et.al. 2013 a). It also promotes deployment where all activities in the software system are assured through interrelated activities. The migration to the cloud and service models are also clearly assured through the CCBF framework (Chang et.al. 2013 a). Specifically, the CCBF has four key areas that make it relevant to the academic community.

The first area is classification. This entails the categorization of diverse business models to offer cloud-adopting organizations relevant strategies and business cases. For instance, the educational community would be allocated its own strategy depending on its courses and other services (Viswanath et al. 2012).

The second relevant area that makes it appropriate is organizational sustainability. According to Vakil et.al (2013), it entails a structured framework that reviews the performance of the institution accurately. Every educational institution would want to operate at the best and most accurate level with the CCBF framework.

The fourth area that makes it relevant to the academic community is portability. Chang et al. (2013a) points out that they would be in a better position to manage the portability of applications to the cloud. With such portability, the academic community would also be in a better position to transfer applications between clouds offered by different vendors.

Lastly, the CCBF is appropriate for academic institutions because of its ability to link various cloud search approaches and service models such as the IaaS, PaaS, SaaS and the Business Models (Borgman et al 2013). Overall, CCBF is justifiable for use in the academic community because of its simulations and ability to address every area.

Apart from this framework, the High Performance Computing (HPC) Framework could also be relevant for educational institutions. Its high computing capabilities and the ability to facilitate research among students puts it at a strategic position in terms of applicability to educational institutions. Again, it gives students the opportunity to access a shared pool of configurable computing resources including servers, networks, storage, and applications.

\section{CLOUD IN EDUCATION: LITERATURE REVIEW}

$\mathrm{Wu}$ (2010) points out that the adoption of the cloud into the field of education has been massive, as many educational institutions have taken the opportunity to maximize on its many advantages. The high level of cloud incorporation into the educational field emanates from its potential to improve efficiency, costs, and to improve convenience in the educational sector. Vakil et al. (2013) reiterates that numerous educational and official establishments in the U.S have continued to recognize the potential of cloud computing in terms of cost reduction and efficiency. The specific reasons that have motivated many educational institutions to adopt cloud computing include:

- The minimization of costs used in the IT infrastructure

- Attainment of efficiency in education delivery

- Improvement of convenience through features such as Pay-per-use

- Enhancement of resource consolidation

- Attainment of green IT

- In light of the above reasons, many universities have gone ahead to adopt cloud computing. For instance, the University of California at Berkley found out the significance of cloud computing in one of their courses that was solely focused on the development and deployment of SaaS applications (Fox, 2009). Donations from the Amazon Web Services (AWS) played an assistive role in helping the university move the course from a locally owned infrastructure to the cloud. It was noted that this would have enabled it acquires a large number of servers within the shortest time possible. This was also an opportunity to enhance resource consolidation at the university.

Economic reasons have pushed some educational institutions to adopt and utilize cloud computing in their learning environments. As noted earlier, cloud computing reduces costs significantly 
because it eliminates costs related to the development and maintenance of massive IT infrastructure (Jang, 2014).

- In line with economic conditions and the need to minimize costs, institutions such as the Washington State University's School of Electrical Engineering and Computer Sciences (EECS) have been forced to embrace cloud computing to cut down their operational costs. They were able to select the vSphere4 platform, which is flexible, dynamic, reliable, and offers seamless maintenance of the IT infrastructure (Fox 2009). Learning and research has been simplified through the cost rationalization approach, which recognizes the need to do more with less.

Cloud computing in education has been applied internationally in numerous educational institutions starting from primary schools to universities. Schools in European countries such as Britain have adopted the cloud in their educational system hence enhancing efficiency.

- Hicks (2009) affirms that some of the common examples of U.K universities that have been able to incorporate cloud computing into their academia include the Leeds Metropolitan University and the University of Westminster. The key factors for the move to the cloud was cost reduction and the enhancement of reliability in the use of computing services (Shin et al. 2014). They have also based three reasons on the need to enhance green IT in their learning environment. This has led to proper functioning and flexible operations in terms of research and academics.

African educational institutions have not been left behind in terms of using the cloud in their research and learning. The lack of an adequate IT infrastructure and the inability to cope with software and hardware upgrades have contributed to the adoption of the cloud in many African educational establishments (Truong et al. 2012).

- With the help of Google, institutions such as the University of Nairobi in Kenya and the National University of Rwanda have embraced cloud computing. This has enhanced information sharing among students and has been critical to the minimization of costs related to IT maintenance, enhancement of flexibility, and resource consolidation. Microsoft is also helping Ethiopia roll out the project of distributing 250,000 laptops all operating on Microsoft's Azure Cloud platform (Sultan, 2010)

Therefore, the critical benefits of using cloud computing in education could be summarized as below.

1. Lower capital costs for institutions. Erkoç and Kert (2012) reiterate that this is especially because educational institutions have the opportunity to offer a wide variety of services while only paying for the actual capacity paid

2. It leads to flexibility in the provision of research and academic services because users can access it at any given location in the institution (Fox, 2009).

3. It saves on costs by over $50 \%$ related to the installation and maintenance of IT infrastructure in academic institutions

4. It offers an optimized and customizable IT infrastructure, which offers quick accesses to the desired computing services in the educational institution (Almorsy et al. 2011)

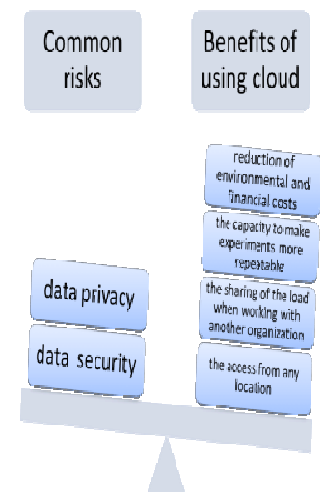

Fig 3: Deploying Cloud Computing in Education:benefits \& common risks

However, there are several risks associated with the use of cloud computing in the academic community. Common risks of using cloud computing in education include:

- The cloud is always subject to the risk of virtual exploits that target both the virtual host and its users. According to Almorsy et al. (2011), the common risks that could be suffered include guest-guest, guesthost, and host-guest virtual threats.

There is always the threat to data privacy and security. The interaction between the cloud provider and the institution poses a major risk to data 
security, especially if the matter has not been critically analyzed (Ercan, 2010).

\section{CLOUD COMPUTING FOR EDUCATION: DEPLOYMENT SCENARIO}

This section presents Cloud Computing for Education. Several factors need to be keenly considered before migration of cloud computing services for education. Katz et al. (2010) reveals that one of the relevant factors for deployment is where the cloud services are to be hosted. The educational institution could choose either the public or private development approach depending on the availability of financial resources to host the cloud within its premises.

The second deployment factor is security. Educational institutions must figure out the kind of data that would be put into the cloud (Lakshminarayanan et. al. 2012). Sensitive information such as the institution's financial information would require a higher level of security. Therefore, they must weigh up the security of the system before deployment.

The third factor for deploying cloud computing in education is customization capabilities. Different educational institutions have different approaches to the learning processes (Mircea \& Andreescu, 2011). Others would want to customize their services and products to students. Therefore, it is vital to understand whether the available cloud computing services are customizable to meet local needs.

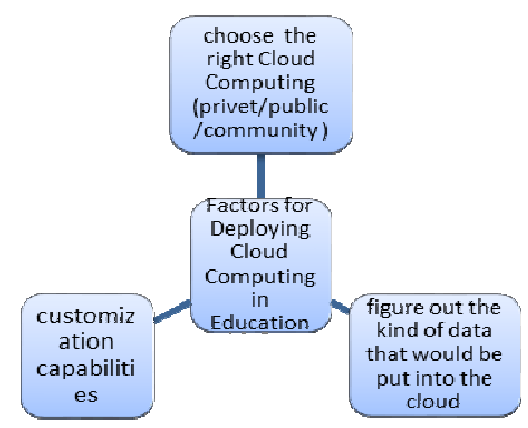

Fig 4: Factors for Deploying Cloud Computing in Education

According to Powell (2010), the fourth factor is the legal requirements relating to the cloud. Educational institutions need to have an in depth understanding of the legal considerations and implications that might arise from security breaches in the cloud.

\subsection{Quality of Service (QoS) and Quality of Experience (QoE) for Leeds Beckett SAS Cloud}

The quality of service (QoS) is primarily used in monitoring the performance of the cloud service without necessarily reflecting the user's quality of experience. However, the quality of experience (QoE) makes up for this by considering the views of the person using cloud services for their activities (Safdari \& Chang, 2014). In the educational sector, the improvement of cloud services could be realized through the quality of experience monitoring approach. This is especially because it tends to focus on the entire service experience and it tends to offer a holistic evaluation of the system rather than focusing on narrowed experiences of users (Safdari \& Chang, 2014). The Leeds Beckett University cloud project is anchored on the ability of combining the cloud with big data techniques. For instance, the cloud project looks forward to the facilitation of matters such as Storage as a Service, Education as a Service, Business Intelligence as a Service, and Integration as a Service (AmreinBeardsley \& Collins, 2012). The Leeds Beckett University cloud project utilizes the SAS Educational Value-Added Assessment System (SAS EVAAS), which has been perceived as the most robust and reliable system available (AmreinBeardsley \& Collins, 2012). Accordingly, it uses SAS for several reasons. Firstly, SAS EVAAS helps lecturers at the university to measure the progress of students and accurately improve the delivery of their instruction. They are always able to modify the curriculum depending on the ability of their students to grasp the content being taught in class (AmreinBeardsley \& Collins, 2012). Additionally, it assists in the alignment of professional goals with the greatest needs of students and hence improving the ability of educators to deliver content. It basically helps in the evaluation of the effectiveness of educators in delivering their content to students. Secondly, policy makers at the university are able to conduct more rigorous longitudinal analysis of the student test results at the university with SAS EVAAS (Amrein-Beardsley \& Collins, 2012). This is attained through the assessment of the accessibility of students to opportunities and services offered through the cloud. The educational 
environment would be more efficient with the use of the SAS in their cloud computing system because of the enhancement of teaching strategies and student success.

\section{A CASE STUDY AT LEEDS BECKETT UNIVERSITY}

Since a number of universities do not publish their their Educational Cloud projects publicly, there is a need to disseminate lessons learned and recommendations in the Higher Education. This section presents a case study for Leeds Beckett University's case study of our Cloud project, including the current status, technologies and useful lessons learned.

\subsection{Illustration of Leeds Beckett SAS Cloud}

SAS Cloud has been used as a platform and language for business intelligence (BI) at Leeds Beckett University since Year 2012. The aim is to improve the quality of education and students' experience through the interactive platform provided by SAS. The objective is to develop a master's program in Business Intelligence, which includes modules such as "Business Intelligence, Data Analysis and Visualization" (BIDAV), "Data Warehouse", "Advanced Data Warehouse" and elective modules. Amongst all these modules, BIDAV is the one that provides students both theoretical foundations and practical learning experience, in which students have to learn the SAS programming and use it for developing BI code. BI is a popular topic, in which Chang (2014) has demonstrated how to design, implement and analyze a Business Intelligence in the Cloud to calculate risk and return for financial stock options. The ability to process, interpret and utilize data, as well as understand complex data analysis, is an important skill for employability. Similarly BI concepts can be fully transferable to Higher Education to ensure that students can equip with numeracy, quantitative and analytical skills required by employers. With more training in place, students can build up their competency and demonstrate their BI portfolios and services. They can import their datasets directly into SAS, which have built-in libraries and server connected directly to the Cloud in the US. Upon clicking "run", their code will be executed directly on the SAS Cloud in the US as shown in Figure 5.

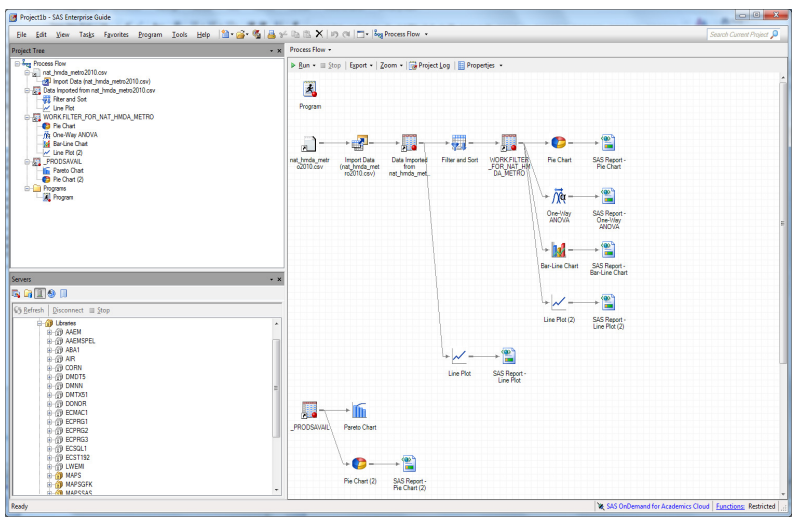

Fig 5: A screenshot about SAS Cloud

Students can receive all their data analysis results, interpretation and visualization in one go with less than 10 seconds of waiting time. Table 1 shows an example for SAS syntax. SAS is a procedure-driven language, meaning that all the steps have been predefined. The emphasis is to show a list of useful procedures to students and explain how they can be used in different cases. In Table 1, "autoreg" is a procedure to perform regression which can generate statistical tests and data analysis simultaneously. All these take a matter of seconds for students. The data used for analysis is called "pred", which uses autoreg for computation and then calculates the residual (the sum of all the differences between all datapoints and regression line) from the statistical.

\subsection{Data Visualization}

Data Visualization is an important aspect in learning business intelligence, in which students can directly understand the interpretations of data and its correlations with other aspects of data analysis. Since there are several statistical results and tests, it is difficult for some students to understand the meanings of all these outputs (Chang, 2014). Hence, the use of data visualization is extremely useful for students to understand complex datasets and their correlations to other data. According to our experience, students can understand the module, BIDAV , much quicker than using traditional means of learning. In order to understand the benefits and long-term implications, questionnaires will be designed to identify the improvement in learning efficiency and student satisfaction in our next phase of research. Figure 6 shows the screenshot of a data visualization output, where all the key results can be computed simultaneously along with different types of statistical tests. 


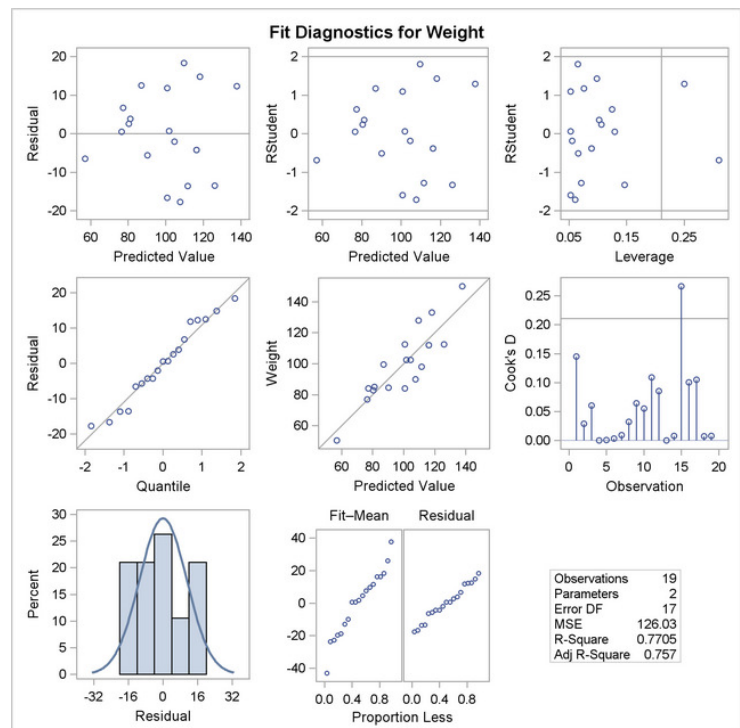

Fig 6: An example of data visualization with statistical tests and key outputs

\subsection{DISCUSSION}

Overall, it is clear that cloud computing is directly applicable to the educational sector because of the significant role it plays in boosting learning and research processes among students. The community cloud is the most recommendable because of its ability to consider the costs dedicated to IT infrastructure within learning institutions. The sharing of resources plays an instrumental role in ensuring that costs are minimized in the best ways possible (Lakshminarayanan et. al. 2012). The adoption of cloud compution at Leeds Beckett University provides a reliable case study for the best ways to adopt and implement cloud computing within educational institutions. The main aim of using SAS at the institution is to improve the educational outcomes of students through closer monitoring by lectures. Hence, significant efforts will be made for future research to explore the best cloud computing frameworks being instrumental in boosting educational outcomes in educational institutions (Viswanath et al. 2012). Furthermore, there should be an exploration of how costs could be minimized through resource sharing among educational institutions in their sharing of cloud services. This will make it easier for institutions to implement the project without being limited by their tight budgets or financial situation. Another approach is to use an implementation framework to ensure that all Cloud services can be delivered on time (Chang et al. $2013 \mathrm{~b}$ ). The example include the integration between Education as a Service and Storage as illustrated by Chang et al. (2013 b).

\section{CONCLUSION}

In conclusion, cloud computing is geared toward transforming the educational field through efficient and reliable operations. Sharma and Ganpati (2013) conclude that the ability of cloud computing to reduce overall costs relating to IT infrastructure and its capacity to boost data access at any given location in educational institutions has been crucial in promoting its adoption and usage in the educational field. Universities such as the University of Greenwich have been on the forefront of adopting cloud computing and using it for research and educational services. Additionally, Leeds Beckett University's SAS Cloud system has worked more efficiently by giving lecturers the opportunity to accurately monitor the progress of its students in education and research. The educational field around the world is gradually becoming technological thanks to the evolution of cloud computing. The reliability and efficiency of cloud computing presents hope for the continuous growth of the educational sector. However, educational institutions need to beware of the common risks they could face while utilizing cloud computing, such as virtual threats and the loss of vital information. There needs to be clear communication with the cloud providers to mitigate such risks and benefit continuously from the cloud in terms of minimal capital costs, flexibility, and the provision of customized services to students.

\section{References}

Almorsy M, Grundy, J \& Ibrahim, AS 2011, 'Collaboration-based cloud computing security management framework,' IEEE International Conference on Cloud Computing, pp. 1-8.

Amrein-Beardsley, A \& Collins, C 2012, 'The SAS Education Value-Added Assessment System (SAS EVAAS) in the Houston Independent School District (HISD): Intended and Unintended Consequences,' Educational Policy Archives, vol. 20, no. 12, pp. 1-31.

Avram, MG 2014, 'Advantages and challenges of adopting cloud computing from an enterprise perspective,' Procedia Technology, Volume 12, pp. 529 - 534.

Borgman, HP, Bahli, B, Heier, H \& Schewski, F 2013, 'Cloudrise: Exploring cloud computing adoption and governance with the TOE framework,' 46th Hawaii International Conference on System Sciences, pp. 44254435. 
Chang, V., Walters, R. \& Willis, G. 2013a , 'The development that leads to the Cloud Computing Business Framework,' International Journal of Information Management, vol. 33, no. 3, pp. 524-538.

Chang, V., Walters, R. J., \& Wills, G. 2013 b. 'Cloud Storage and Bioinformatics in a private cloud deployment: Lessons for Data Intensive research'. In Cloud Computing and Services Science (pp. 245-264). Springer International Publishing.

Chang, V \& Wills, G. 2013, 'A University of Greenwich case study of cloud computing: Education as a service,' IGI Global Disseminator of Knowledge, vol. 1, no. 1, pp. $1-22$.

Chang, V. 2014. 'The Business Intelligence in the Cloud', Future Generation Computer Systems, 37, 512-534.

Chen, SL, Chen, YY \& Hsu, C 2014, 'A new approach to integrate internet-of-things and software-as-a-service model for logistic systems: A case study,' Sensors, vol. 14 , no. 4 , pp. 6144-6164.

Bright, P. 2011, 'Amazon's lengthy cloud outage shows the danger of complexity', [Internet], Available from: $<$ http://arstechnica.com/business/2011/04/amazonslegthy-outage-shows-the-danger-of-complexity/> [Accessed 15-September-2013].

Ercan, T 2010, 'Effective use of cloud computing in educational institutions,' Procedia Social and Behavioral Sciences, vol. 2, no. 1, pp. 938-942.

Erkoç, MF \& Kert, SB, 2012, 'Cloud computing for distributed university campus: A prototype,' International Conference The Future of Education, pp. 1-4.

Fox, A 2009, 'Cloud computing in education,' Viewed 24 February 2015, $<$ https://inews.berkeley.edu/articles/Spring2009/cloudcomputing >

Géczy, P. Izumi, K. , and Hasida, k. (2013), 'Hybrid Cloud Management: Foundation and Strategies', National Institute of Advanced Industrial Science and Technology.

Koetsier,J. (2013). '10 million Malaysian students, teacher, and parent will now use Goggle Apps for Education', [Internet], Available from: $<$ http://venturebeat.com> [Accessed 12-June-2013].

Hicks, B 2009. UK universities put their faith in the Google cloud, ' viewed 24 February 2015, $<$ http://www.agent4change.net/resources/open- source/280-uk-universities-put-their-faith-in-the-googlecloud.html>

Ivanus, C \& Iovan, S 2014, 'Cloud computing technology trends,' Fiability \& Durability / Fiabilitate Si Durabilitate, Volume 1, pp. 264-269.

Jang, S 2014, 'Study on service models of digital textbooks in cloud computing environment for SMART education,' International Journal of $u$ - and e-Service, vol. 7, no. 1 , pp. $73-82$.

Jula, A, Sundararajan, E \& Othman, Z 2014, 'Cloud computing service composition: A systematic literature review,' Expert Systems with Applications, vol. 41, no. 8, p. 3809-3824.

Katz, R, Goldstein, P \& Yanosky, R 2010, 'Cloud computing in higher education,' Article, pp. 1-12.

Kurelović, K, Rako, S \& Tomljanović, J 2013, 'Cloud computing in education and student needs,' $M I P R O$, vol. 2, no. 2, pp. 856-861.

Lakshminarayanan, R, Kumar, B \& Raju, M 2012, 'Cloud computing benefits for educational institutions,' Higher College of Technology, pp. 1-7.

Mircea, M \& Andreescu, AI 2011, 'Using cloud computing in higher education: A strategy to improve agility in the current financial crisis,' IBIMA Publishing , Volume 2, pp. 1-15.

Mokhtar, SA, et al 2013, 'Cloud computing in academic institutions,' ICUIMC, pp. 1-7.

Powell, J 2010, 'Cloud computing - what is it and what does it mean for education?,' Leicester Business School, pp. 1-8.

Safdari, F \& Chang, V. 2014, 'Review and analysis of cloud computing quality of service,' School of Computing, pp. 1-7.

Sharma, AK \& Ganpati, A 2013, 'Cloud computing: An economic solution to higher education,' International Journal of Application or Innovation in Engineering \& Management (IJAIEM), vol. 2, no. 3, pp. 200-206.

Shin, J, Jo, M, Lee, J \& Lee, D 2014, 'Strategic management of cloud computing services: Focusing on consumer adoption behavior,' Engineering Management, IEEE Transactions, vol. 61, no. 3, pp. 419 - 427.

Singhal, M et al, 2013, 'Collaboration in multicloud computing environments: Framework and security issues,' IEE Transactions on Cloud Computing, vol. 46, no. 2, pp. 75-84. 
Sultan, N 2010, 'Cloud computing for education: A new dawn?,' International Journal of Information

Management, vol. 30, no. 1, pp. 109-116.

Truong, HL, Pham, TV, Thoai, N \& Dustdar, S 2012,

'Cloud computing for education and research in developing countries, 'IGI Globa, pp. 78-94.

Ukil, A, Jana, D \& Sarkar, AD, 2013, 'A security framework in cloud computing infrastructure,' International Journal of Network Security \& Its Application, vol. 5, no. 5, pp. 11-24.

Vakil, F, Lu, V \& Russkoff, A, 2013, 'Recent developments in cloud computing and high speed connections for business practices,' Review of Business, vol. 33, no. 1, pp. 111.

Viswanath, D, Kusuma, S \& Gupta, SK 2012, 'Cloud computing issues and benefits modern education,' Global Journal of Computer Science and Technology Cloud \& Distributed, vol. 12, no. 10, pp. 1-7.

$\mathrm{Wu}, \mathrm{CF} 2010$, 'Impact on applying cloud computing service to IT education,' Department of Information Management, Volume 168, pp. 170-175.

Yang, H \& Tate, M 2012, 'A descriptive literature review and classification of cloud computing research,'

Communications of the Association for Information Systems, Volume 31, pp. 35-60.

Youssef, AE 2012, 'Exploring cloud computing services and applications, 'Journal of Emerging Trends in Computing and Information Sciences, vol. 3, no. 6, pp. 838-848. 